\title{
MicroscopyPioneers
}

\section{Mike Marko: \\ Preserving the Past and Shaping the Future}

\section{Cameron Varano}

The Pennsylvania State University, 201 Old Main, University Park, PA 16802

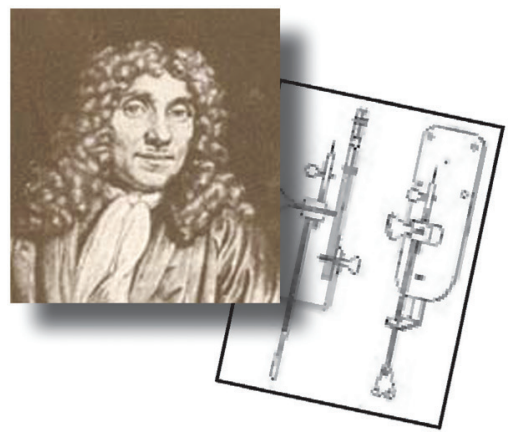

cvarano@psu.edu

Michael Marko was born in Philadelphia, Pennsylvania. His childhood was spent in New York, partly in Yonkers, but mostly in Glen Falls, a community known as "Hometown USA," situated next to Lake George and about an hour north of the state's capital. In the 1950s his family spent a few years in a suburb of Detroit where, at one of GM's "Futurama" events, he saw his first TEM and recalls thinking that he hoped to involve himself with such instrumentation someday. Looking back, he realized that it was an RCA EMU3, which was the first TEM he used as a student. He returned to Albany, New York, where he has spent most of his life, and at age 13 he got his amateur radio license. As noted in Sterling Newberry's 1990 interview with James Hillier, Hillier observed that many electron microscopists began as children with building radios and also learned German, the language of most publications on EM in the early days. Mike still maintains a fluent proficiency in German by frequent visits to European friends and continues with "ham radio."

Marko earned his bachelor's degree from the State University of New York at Albany in Biophysics and started using EM professionally in 1973. In 1976, he took a position under D.F. Parsons at the Electron Optics Lab at Wadsworth Center in Albany during its founding, where an AEI EM-7 one-million-volt TEM was being installed. Marko has been a Research Scientist at Wadsworth since 1976, although he is now also an adjunct professor at the SUNY Polytechnic Institute, College of Nanoscale Science and Engineering.

The HVEM is still intact at Wadsworth (Figure 1), although it has not been used since 2014. The retirement of old equipment is a bit sad for Marko, consequently many TEMs and LMs find retirement in his home lab. The HVEM, and even his JEM4000 are too large, so his home lab houses only $100 \mathrm{kV}$ TEMs (Figure 2). For perspective, we should all bear in mind that most homes are at best equipped with a simple light microscope.

Professionally, Marko's interest lies not with specific biological mechanisms, but the technology needed to investigate them. Until Marko published his groundbreaking work in Nature Methods in 2007, the scientific community was limited in its ability to use cryo-EM with thicker vitreously frozen biological specimens. The methodology to section thin samples, cryo-ultramicrotomy, had drawbacks including material-dependent compression and poor adhesion to a substrate, which made cryo-electron tomography (cryo-ET) problematic. In materials science, FIB-milling had long been a common thinning method. However, the world of biological EM doubted that vitreous material could survive the gallium beam. Marko observed that when the beam cuts at a glancing angle, the ablation/implantation depth is minimal, even for a frozen specimen. When asked what allowed for such bold thinking, he humbly brushed off the compliment and stated it was a simple matter of understanding that ice is simply another material. As proof of concept he, along with his collaborators, successfully milled intact vitreously frozen $E$. coli bacteria down to "TEM transparency" for subsequent cryo-ET. This technique was further developed in Germany and is now a major research tool in cryo-EM, as cryo-ET is the only high-resolution means of directly studying molecular interactions within a cell.

We discussed how he sees the field of electron microscopy as a pendulum oscillating between technology development and biological application. Marko is now focused on developing the workflow of CryoFIB and cryo-CLEM to ensure that it can be easily used to effectively answer biological questions. Specifically, he is working to design a holder that will fit in the FIB, a cryo light microscope and the cryo-TEM for cryo-ET (Figure 3). In Marko's opinion, it is important to see macromolecules in their native environment. He is also exploring the use of single-layer graphene as a phase plate to avoid some of the limiting effects of current phase plate technology for cryo-EM.

2007 was a big year for Marko because, along with the publication of his FIB-milling technique, he served as Program Chair for the annual Microscopy \& Microanalysis meeting in Fort Lauderdale, Florida. He was later elected as a Director of MSA and then served as MSA President in 2016. During this time, he maintained an active research portfolio, funded by three NIH grants. He currently serves as the Society's Archivist, a bridge to the past and the future of the Society. Scientific societies such as MSA are the keepers of the publications of many seminal findings. Marko is working with Cambridge University Press to ensure that all the annual M\&M meeting Proceedings are digitized and made more widely available. Marko, along with Charles Lyman, has led the effort for MSA to become an Affiliate of the Science History Institute (SHI) in Philadelphia. SHI is now the keeper of most of MSA's archives, and Marko recently sent them 102 boxes of material. His home lab serves as a bit of a museum of electron microscopy and electronic equipment of the 1950s and 1960s. When I suggested that he is a historian, he disagreed. He 

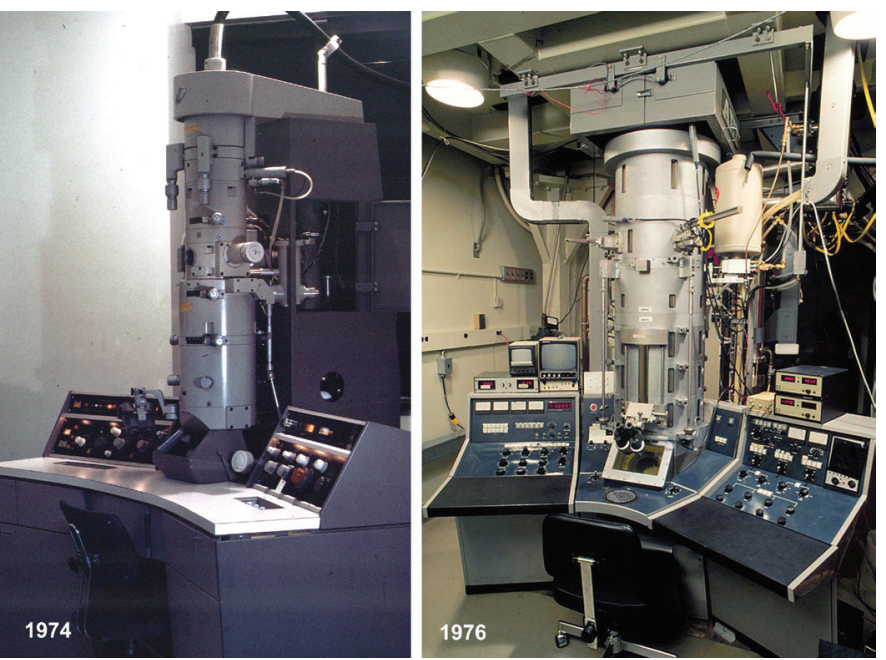

Figure 1: His first "professional" TEM, a JEM-100B used in neuroscience research in 1974. The Albany AEI EM7 HVEM, his reason for moving to Wadsworth in 1976. Marko and the HVEM are still there!

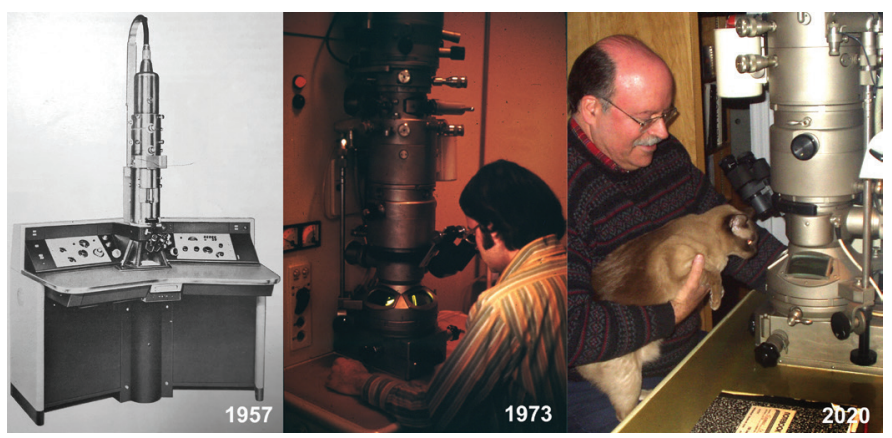

Figure 2: The first TEM ever seen (and the first used), a 1957 RCA EMU3. The first "good" TEM used in 1973 as a student (an Elmiskop la). A 1964 Siemens Elmiskop la, one of three in the 2020 home lab. His cat (Mui) watches the specimen move on the stage.

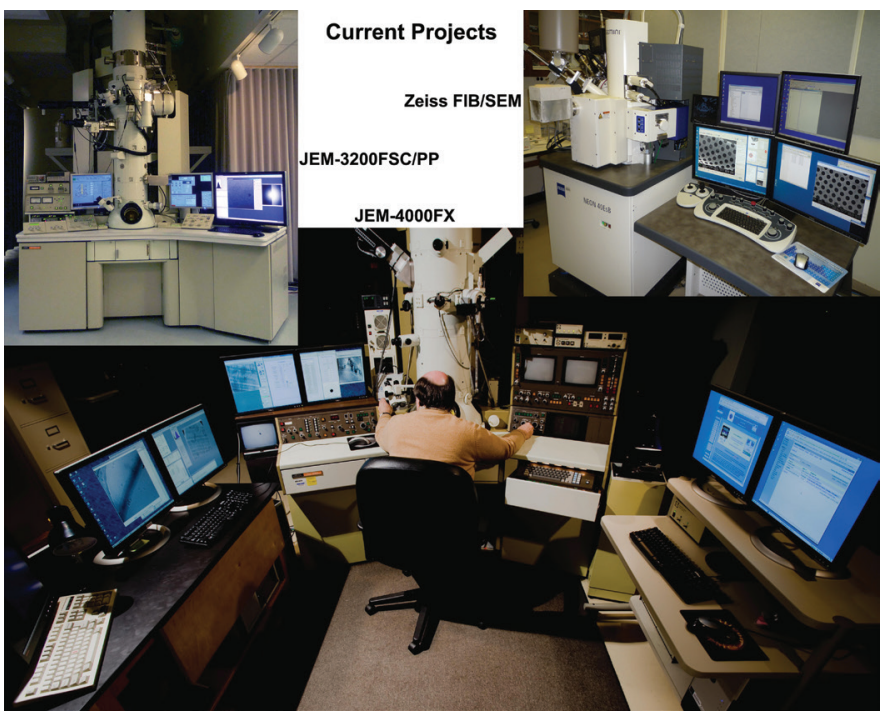

Figure 3: Current EMs used at Wadsworth. The JEM-3200FSC/PP was customdesigned at the JEOL factory for phase-plate work. The Zeiss FIB/SEM is used for cryo-CLEM. The much-modified JEM-4000FX is still Marko's favorite TEM. sees himself as a hoarder, meaning that he collects the items and information, but is not the one to put it together. His noted exception is the memorial poster collection displayed at M\&M meetings and in MSA webpages. Besides providing information as requested by historians, he records interviews with the Society's Distinguished Scientists at M\&M meetings.

Marko also mentors and supports the development of emerging leaders within the society, and willingly shares his experiences and insights with younger members. Alice Dohnalkova attests to his willingness to incorporate earlyto mid-career folks into the community. She remembers being a new member of the Society and feeling that her first M\&M meeting was a bit overwhelming. She was fortunate enough to meet Mike at the meeting. He was sure to include and introduce her to fellow members. These introductions sparked professional relationships, which turned into email correspondence throughout the years. In 2019, Alice served as Program Chair for the annual meeting. Again, Mike was there to provide advice and bolster confidence.

Throughout his career, Mike has provided direction in the field of microscopy research and development, as well as educational outreach and guidance. He has earned a reputation as a dedicated and perennial figure who bridges the past and the future. For his pioneering contributions to the scientific community and dedicated long-term service to the Microscopy Society of America, he was elected an MSA fellow in 2019.

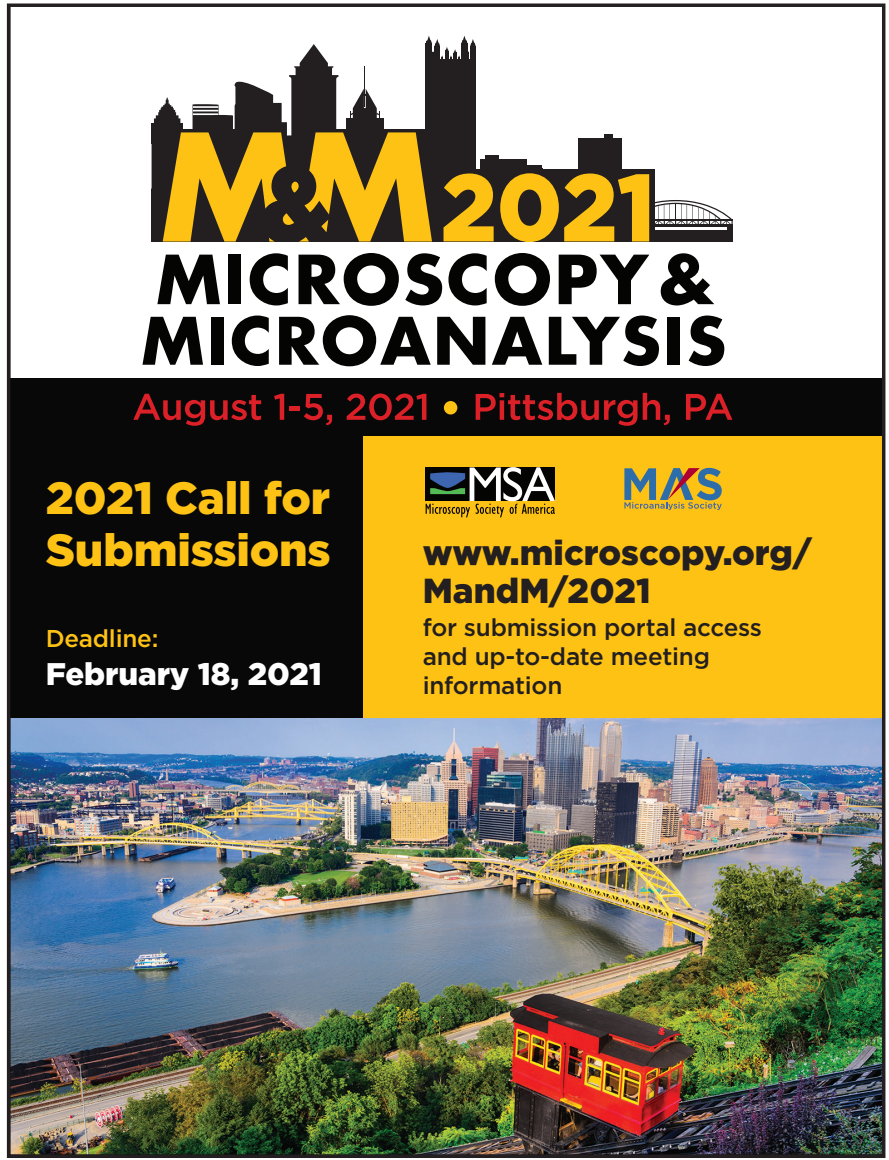

